Proceedings

\title{
Design, Simulation and Fabrication of A Novel MEMS Based Pulsometer ${ }^{\dagger}$
}

\author{
Xingzhe Zhang *, Arnesh Bose, Dinesh Maddipatla, Binu Narakathu, Vikram Turkani and \\ Massood Atashbar
}

Electrical and Computer Engineering, Western Michigan University, Kalamazoo, MI 49008, USA; arneshkumar.bose@wmich.edu (A.B.); dinesh.maddipatla@wmich.edu (D.M.); binubaby.narakathu@wmich.edu (B.N.); vikramshreeshail.turkani@wmich.edu (V.T.); massood.atashbar@wmich.edu (M.A.)

* Correspondence: xingzhe.zhang@wmich.edu; Tel.: +1-269-366-2341

† Presented at the Eurosensors 2018 Conference, Graz, Austria, 9-12 September 2018.

Published: 3 December 2018

\begin{abstract}
A novel pulsometer was successfully developed using microelectromechanical systems (MEMS) based silicon-on-glass (SOG) technology for biomedical applications. The sensor was modelled and simulated in COMSOL Multiphysics ${ }^{\circledR}$ for pressures ranging from 0 to $40 \mathrm{mmHg}$. The capability of the fabricated pulsometer to detect movements in $\mathrm{x}$ and $\mathrm{z}$-axis directions was investigated. The simulation results demonstrated displacement changes as high as of $98 \%$ and $36 \%$ in the $\mathrm{x}$ and z-axis directions, respectively for $40 \mathrm{mmHg}$, which correspond to typical radial blood pressure (rBP) on the wrist. In addition, an average capacitance change of $1 \mathrm{nF}$ was experimentally obtained in the $\mathrm{x}$-axis direction, from $-5 \mathrm{~V}$ to $5 \mathrm{~V}$. The response of the pulsometer is analyzed and presented in this paper.
\end{abstract}

Keywords: capacitive sensor; COMSOL simulation; microelectromechanical systems (MEMS); pulsometer; silicon-on-glass (SOG)

\section{Introduction}

Pulsometers, which are capable of detecting both blood pressure and heart rate, have been used for monitoring human cardiovascular conditions [1]. Pulsometers are fabricated using microelectromechanical systems (MEMS) based silicon-on-glass (SOG) technology. Typically, pulsometers are based on bridge structures and, therefore, suffer from low sensitivity and narrow functionality, due to displacement only in one axial direction [2-6]. Also, these devices require precision etching time and rate, to maintain accurate etch depth, and often consists of four or more layers, thus making them relatively expensive. To mitigate the drawbacks of the current pulsometer design and fabrication methods, a cantilever based pulsometer with high sensitivity and multifunctionality is developed. A cantilever based structure is envisioned to provide better sensitivity due to displacement in both $\mathrm{x}$ and $\mathrm{z}$-axis directions. In this study, the capability of a novel cantilever based pulsometer is investigated using multiphysics simulation and experimental methods.

\section{Methodology}

\subsection{Design}

A schematic of the pulsometer is shown in Figure 1. The pulsometer was designed in AutoCAD ${ }^{\circledR}$, with an overall dimension of $2 \times 2 \times 0.6 \mathrm{~mm}$, using a comb-electrode configuration. The pulsometer consists of a glass substrate, silicon wafer and contact metal pads. The device has a terminal electrode 
and ground electrode. The terminal electrode or cantilever structure consists of flexible beams $(4 \mu \mathrm{m}$ wide), proof mass $(1.5 \times 0.6 \mathrm{~mm})$ and a set of movable comb electrodes. The set of fixed electrodes are located on the ground electrode. The comb-electrodes have 88 interdigitated fingers with electrode width and pitch of $10.1 \mu \mathrm{m}$ and $18.0 \mu \mathrm{m}$, respectively.

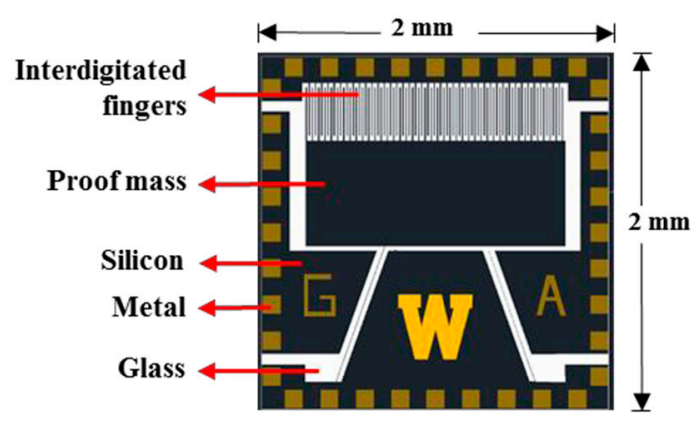

(a)

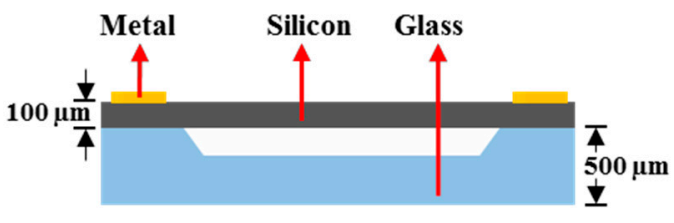

(b)

Figure 1. Schematic of the pulsometer: (a) top view and (b) side view.

\subsection{Working Principle}

The working principle of the pulsometer is based on detecting the capacitance change between the ground electrode and the terminal electrode. When a pressure is exerted on the pulsometer, the cantilever structure moves and, therefore, causes a dynamic capacitance change in the terminal electrode due to its displacement from the initial position in the $\mathrm{x}$ - or $\mathrm{z}$-axis directions. The spring constant of the cantilever beams is mathematically calculated using Equation (1) [7].

$$
k=\frac{E W H^{3}}{4 L^{3}}
$$

where, $\mathrm{E}$ is the Young Modulus, $W$ is the width, $\mathrm{H}$ is the thickness and $\mathrm{L}$ is the length of the cantilever structure. The deflection of the terminal electrode, which is dependent on the spring constant of the cantilever beam can be calculated using Equation(2).

$$
\Delta \mathrm{x}=\frac{F_{\text {load }}+F_{\text {self }} \text {-weight }}{K}
$$

where, $F_{\text {self-weight }}$ is the self-weight of the terminal electrode and the $F_{\text {load }}$ is the load force exerted on top of the terminal electrode. The load force exerted by the pulse pressure on the pulsometer can be calculated using Equation (3).

$$
F_{\text {load }}=P_{\text {pulse }} \times A_{\text {terminal }}
$$

where, $P_{\text {pulse }}$ is the pulse pressure and $A_{\text {terminal }}$ is the top surface area of the terminal electrode. Therefore, from Equations (2) and (3), it can be concluded that the pulse pressure is directly proportional to the deflection of the terminal electrode.

\subsection{Fabrication}

The glass substrate was initially etched using hydrofloric acid (HF) to obtain an air recess of 3 $\mu \mathrm{m}$ (Figure 2a). The silicon wafer was anodically bonded to the glass substrate at $300{ }^{\circ} \mathrm{C}$ using two electrodes with a potential difference of $1 \mathrm{kV}$ (Figure $2 \mathrm{~b}$ ). The terminal and ground electrode was patterned using deep reactive-ion etching (DRIE), etching away the targeted silicon for final release of structure (Figure 2c). Aluminum (Al) contact pads were finally deposited on the silicon layer (Figure 2d). 


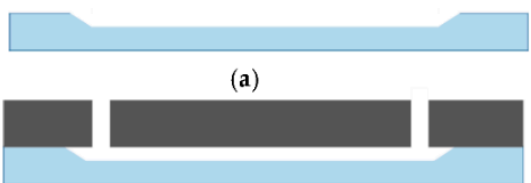

(c)

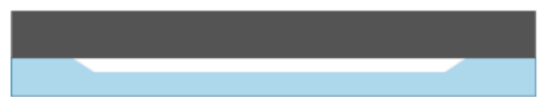

(b)

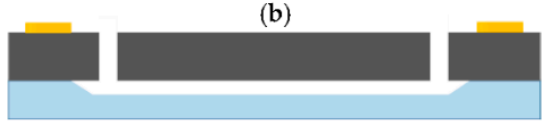

(d)

Figure 2. (a) Etching glass to form recess, (b) anodic bonding of the glass substrate and silicon wafer, (c) DRIE pattern process and (d) deposition of metal contact pads.

\section{Results and Discussion}

The response of the pulsometer was investigated by simulating the designed cantilever structure in COMSOL Multiphysics ${ }^{\boxplus}$ simulation software using the solid mechanics module. The simulations were performed for an applied pressure range from 0 to $40 \mathrm{mmHg}$, which corresponds to the typical radial blood pressure $(\mathrm{rBP})$ on the wrist [8]. As the pressure was increased from 0 to $40 \mathrm{mmHg}$, a maximum displacement of $9.8 \mu \mathrm{m}$ and $36 \mu \mathrm{m}$ was observed in the $\mathrm{x}$ and z-axis directions, respectively (Figure 3a). Based on the displacements, a capacitance change from $39 \mathrm{pF}$ to $20 \mathrm{pF}$ and $1950 \mathrm{pF}$ was theoretically calculated in the $\mathrm{x}$ and $\mathrm{z}$-axis directions, respectively. As an example, the displacements for an applied pressure of $5 \mathrm{mmHg}$ in the $\mathrm{x}$ and z-axis directions are shown in Figure 3b,c, respectively. The results demonstrated a maximum displacement of $2 \mu \mathrm{m}$ and $4.8 \mu \mathrm{m}$ in the $\mathrm{x}$ and $\mathrm{z}$-axis directions, respectively. In addition, the displacement distribution throughout the cantilever structure was also investigated by applying the typical $\mathrm{rBP}$ of $40 \mathrm{mmHg}$. It was observed that the maximum displacement of $36 \mu \mathrm{m}$, in the z-axis direction, was obtained at the comb-electrodes (Figure 3d).

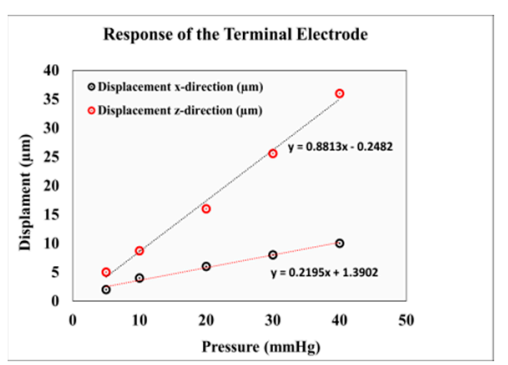

(a)

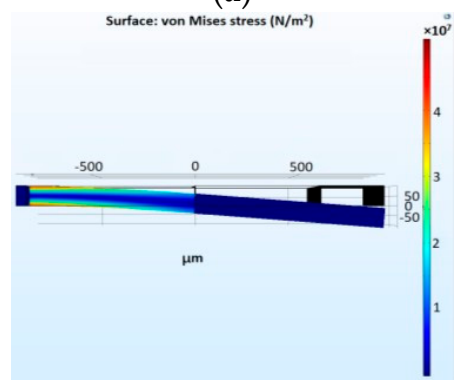

(c)

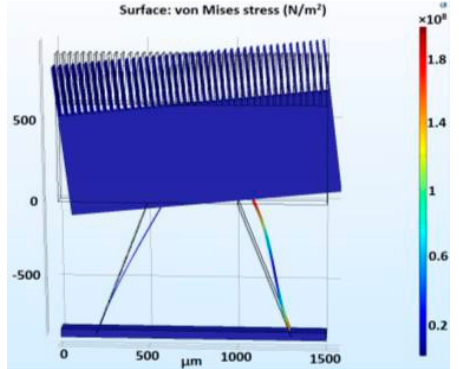

(b)

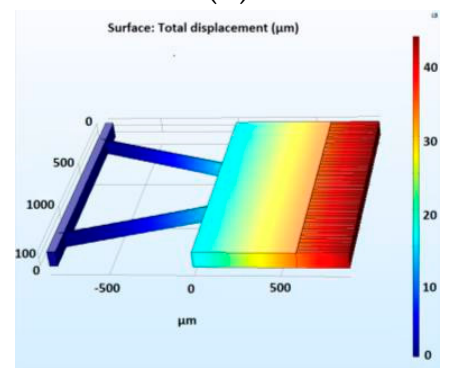

(d)

Figure 3. Displacement of the cantilever structure: (a) in $x$ and $z$-axis directions for varying pressure $(0-$ $40 \mathrm{mmHg}$ ), (b) in $\mathrm{x}$-axis direction for $5 \mathrm{mmHg}$ pressure, (c) in z-axis direction for $5 \mathrm{mmHg}$ pressure, and (d) displacement distribution in z-axis direction for $40 \mathrm{mmHg}$ pressure.

The fabricated pulsometer was connected to a SEMIPROBETM PS4L-M6 probe station using a probe card (Figure 4a). The pulsometer was characterized in the $\mathrm{x}$-axis direction by applying a voltage sweep from -5 to $5 \mathrm{~V}$, at $1 \mathrm{KHz}$ frequency, resulting in a capacitance change from $0.2 \mathrm{nF}$ to $1.2 \mathrm{nF}$ (Figure $4 \mathrm{~b}$ ), which corresponds to a capacitance change of $500 \%$. The results obtained thus demonstrate the feasibility of employing the pulsometer for monitoring human cardiovascular conditions in biomedical applications. 


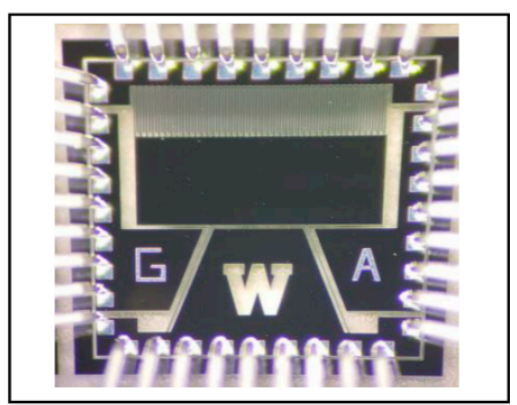

(a)

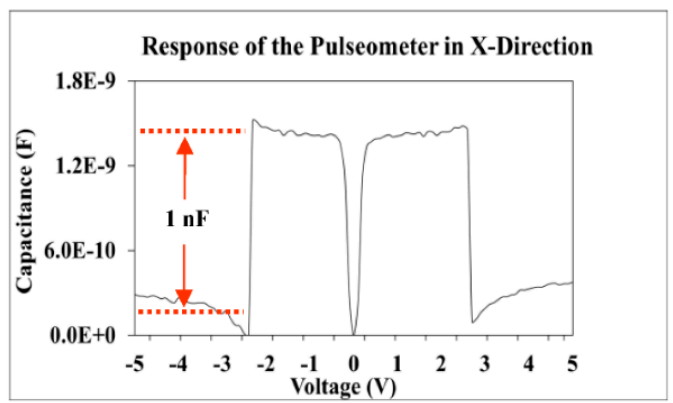

(b)

Figure 4. (a) Fabricated pulsometer connected to probe card and (b) capacitive response of the pulsometer from $-5 \mathrm{~V}$ to $5 \mathrm{~V}$.

\section{Conclusions}

In this work, a novel pulsometer was successfully modelled and simulated in COMSOL Multiphysics ${ }^{\circledR}$ for pressures ranging from 0 to $40 \mathrm{mmHg}$. In addition, the pulsometer was also fabricated using MEMS based SOG technology. Simulations performed using the solid mechanics module demonstrated displacement changes as high as of $98 \%$ and $36 \%$ in the $\mathrm{x}$ and $\mathrm{z}$-axis directions, respectively for $40 \mathrm{mmHg}$, which correspond to typical radial blood pressure (rBP) on the wrist. Using the fabricated pulsometer, an average capacitance change of $1 \mathrm{nF}$ was experimentally obtained in the $\mathrm{x}$-axis direction, from $-5 \mathrm{~V}$ to $5 \mathrm{~V}$. Future work is in progress to enhance capability of the fabricated pulsometer by integrating it into a portable and real-time field deployable system for monitoring human cardiovascular conditions.

Acknowledgments: The authors would like to acknowledge access to Lurie Nanofabrication Facility (LNF) at University of Michigan and James Ricker for fabricating the devices.

\section{References}

1. Inan, O.T.; Migeotte, P.F.; Park, K.S.; Etemadi, M.; Tavakolian, K.; Casanella, R.; Zanetti, J.M.; Tank, J.; Funtova, I.; Prisk, G.K.; et al., Ballistocardiography and Seismocardiography: A Review of Recent Advances. IEEE J. Biomed. Health Inform. 2015, 19, 1414-1427, doi:10.1109/JBHI.2014.2361732.

2. Ainsworth, B.; Cahalin, L.; Buman, M.; Ross, R. The Current State of Physical Activity Assessment Tools. Prog. Cardiovasc. Dis. 2015, 57, 387-395, doi:10.1016/j.pcad.2014.10.005.

3. Koivisto, T.; Pänkäälä, M.; Hurnanen, T.; Vasankari, T.; Kiviniemi, T.; Saraste, A.; Airaksinen, J. Automatic Detection of Atrial Fibrillation using MEMS accelerometer. In Proceedings of the Computing in Cardiology Conference, Nice, France, 6-9 September 2015; pp. 829-832, doi:10.1109/CIC.2015.7411039.

4. Atashbar, M.Z.; Bazuin, B.J.; Simpeh, M.; Krishnamurthy, S. 3-D finite-element simulation model of SAW palladium thin film hydrogen sensor. In Proceedings of the IEEE International Frequency Control Symposium and Exposition, Montreal, QC, Canada, 23-27 August 2004; pp. 549-553, doi:10.1109/FREQ.2004.1418517.

5. Gangadaran, S.; Varadan, V.V.; Varadan, V.K.; Jose. K.A.; Atashbar, M.Z. Love-wave-based Ice Sensor. In Proceedings of the Symposium Smart Materials Sensors 1999, Newport Beach, CA, USA, 20 July 1999; pp. 287-294, doi:10.1117/12.354279.

6. Koivisto, T.; Pankaala, M.; Hurnanen, T.; Vasankari, T.; Kiviniemi, T.; Saraste, A.; Airaksinen, J. Automatic Detection of Atrial Fibrillation using MEMS accelerometer. In Proceedings of the Computing in Cardiology Conference (CinC), Nice, France, 6-9 September 2015; pp. 829-832, doi:10.1109/CIC.2015.7411039.

7. Saha, S.C.; Hanke, U.; Jensen, G.U.; Saether, T. Modeling of Spring Constant and Pull-down Voltage of Non uniform RF MEMS Cantilever. In Proceedings of the IEEE International Behavioral Modeling and Simulation Workshop, San Jose, CA, USA, 14-15 September 2006; pp. 56-60, doi:10.1109/BMAS.2006.283470. 
8. Parati, G.; Stergiou, G.; O’brien, E.; Asmar, R.; Beilin, L.; Bilo, G.; Clement, D.; De La Sierra, A.; De Leeuw, P.; Dolan, E.; et al. European Society of Hypertension practice guidelines for ambulatory blood pressure monitoring. J. Hypertens. 2014, 32, 1359-1366, doi:10.1097/HJH.0000000000000221.

(c) (

(C) 2018 by the authors. Licensee MDPI, Basel, Switzerland. This article is an open access article distributed under the terms and conditions of the Creative Commons Attribution (CC BY) license (http://creativecommons.org/licenses/by/4.0/). 